\title{
Synthesis of Photoactive Ternary Cadmium Sulfoselenide Thin Film via Cost-effective Chemical Technique for Solar Cell Application
}

\author{
Kishorkumar V Khot ${ }^{1,2 *}$, Dongale TD ${ }^{3}$, Desai ND ${ }^{1}$, Ghanwat VB ${ }^{1}$, Pawar NB ${ }^{1}$, Bagadea CS ${ }^{1}, K^{2}$ amat RK$^{4}$ and \\ Bhosale $\mathrm{PN}^{1 *}$
}

${ }^{1}$ Department of Chemistry, Materials Research Laboratory, Shivaji University, India

${ }^{2}$ Department of Basic Sciences and Humanities, Sharad Institute of Technology, College of Engineering, India

${ }^{3}$ School of Nanoscience and Biotechnology, Shivaji University, India

${ }^{4}$ Department of Electronics, Shivaji University, India

Submission: August 11, 2018; Published: October 04, 2018

*Corresponding author: Kishorkumar V Khot, Department of Chemistry, Materials Research Laboratory, Shivaji University, Kolhapur, India, Email: khotkishor7575@gmail.com;

Bhosale PN, Department of Chemistry, Materials Research Laboratory, Shivaji University, Kolhapur, India, Email: p_n_bhosale@rediffmail.com

\begin{abstract}
We have successfully developed arrested precipitation technique for synthesis of photoactive $\operatorname{Cd}\left(\mathrm{S}_{0.8} \mathrm{Se}_{0.2}\right)$ thin film. Synthesized thin film were characterized for optical, structural, morphological and compositional analysis using UV-Vis spectrophotometer, Xray Diffraction (XRD), Field-Emission Scanning Electron Microscopy (FESEM) and Energy Dispersive Spectroscopy (EDS) analyzer techniques. Optical study shows linear nature of plot confirms direct allowed transition with optical band gap energy $2.13 \mathrm{eV}$. Pure phase hexagonal nanocrystalline thin film formation confirmed through XRD pattern. FESEM micrographs indicate construction of void free and well-adherent twisted nest-like surface morphology containing tremendous grown flakes over substrate. Presence of $\mathrm{Cd}^{2+}, \mathrm{S}^{2-}$ and $\mathrm{Se}^{2-}$ elements confirmed by EDS spectrum. Finally, synthesized thin film show power conversion efficiency of $0.37 \%$.
\end{abstract}

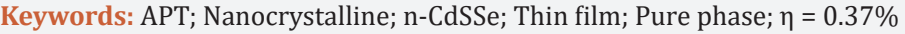

Abbreviations: XRD: Xray Diffraction; FESEM: Field-Emission Scanning Electron Microscopy; CBD: Chemical Bath Deposition; CCGP: Controlled Chemical Growth Process; APT: Arrested Precipitation Technique

\section{Introduction}

In past few years, the world serious energy and environmental crisis have made more attention to development of new cost-effective and sustainable energy source [1]. Also, quest for new alternative renewable energy source is quite argent and necessary. Overall available technologies photoelectrochemical solar cell technology has believed to be cost-effective and renewable energy source for solar energy conversion. Generally, photoelectrochemical performance of semiconducting materials depends on their respective properties and essential physiochemical processes in which, i) Absorption of light radiations, ii) separation of charge carriers, iii) migration of carriers, iv) recombination of charge carriers and $v$ ) redox reaction. Also, respective properties of semiconducting material are nothing but, electronic band structure, crystal structure, chemical constituents and their microstructures.

II-VI group semiconducting compounds are the most important and highly studied semiconducting material for scientific and technological point of application due to their direct band gap [2]. Among this II-VI group semiconducting compounds, typically CdS and CdSe have 2.40 and $1.70 \mathrm{eV}$ optical band gap with wide absorption band edge and excellent absorptivity in visible region [2].

These ternary CdSSe thin films synthesized by varied of method such as, sputtering [3], Chemical Bath Deposition (CBD) method [4] and solvathermal route [5]. All these methods require highly sophisticated instruments, harsh experimental condition, different surface directing agents and solvents [6]. However, in Arrested Precipitation Technique (APT) their no need to use sophisticated instrument, different solvents and harsh experimental condition. Taking into concern these features of technique, we have used APT method for synthesis of CdSSe thin films. APT method is nothing but hybrid chemical process of CBD and Controlled Chemical Growth Process (CCGP) [7]. 
In present investigation, we have successfully deposited $\mathrm{Cd}\left(\mathrm{S}_{0.8} \mathrm{Se}_{0.2}\right)$ thin film using triethanolamine as complexing agent at via APT method. Our intension is to make efficient photoelectrode for photoelectrochemical application using triethanolamine as surface directing agent. Synthesized thin film show $0.37 \%$ power conversion efficiency under illumination of $500 \mathrm{~W}$ tungsten filament lamp (intensity $30 \mathrm{~mW} \mathrm{~cm}^{-2}$ ). Also, thin film formation growth process by using APT is discussed detailed.

\section{Experimental}

\section{Chemicals}

All chemicals were of analytical reagent (AR) grade and used without further purification. Cadmium sulfate hydrate $\left(\mathrm{CdSO}_{4} \cdot \mathrm{H}_{2} \mathrm{O}\right)\left(98 \%, \mathrm{~S}-\mathrm{D}\right.$ Fine Chem.), thiourea $\left(\mathrm{H}_{2} \mathrm{~N}-\mathrm{CS}-\mathrm{NH}_{2}\right)$ (99\%, S-D Fine Chem.) selenium metal powder (99.5\%, Sigma Aldrich), sodium sulfite $\left(\mathrm{Na}_{2} \mathrm{SO}_{3}\right)$ (96\%, S-D Fine Chem.), liquor ammonia $\left(\mathrm{NH}_{3}\right)$ (28-30\% Thomas Baker), and triethanolamine $\left(\mathrm{N}\left(\mathrm{CH}_{2} \mathrm{CH}_{2} \mathrm{OH}\right)_{3}\right)(99 \%$, Merck).

\section{Synthesis of $\mathrm{Cd}\left(\mathrm{S}_{0.8} \mathrm{Se}_{0.2}\right)$ thin film}

In typical synthesis, initially Cd-TEA complex was prepared by triturating 'Cd' with TEA as complexing agent for $6 \mathrm{~h}$ homogenous crushing to form clear Cd-TEA complex. All metal ions and chalcogen ions precursors' concentration is optimized at initial stage of synthesis as $0.05 \mathrm{M}$. Cd-TEA complex release $\mathrm{Cd}^{2+}$ metal ions slowly and react with $\mathrm{S}^{2-}$ and $\mathrm{Se}^{2-}$ chalcogen ions released from dissociation of $\mathrm{H}_{2} \mathrm{~N}-\mathrm{CS}-\mathrm{NH}_{2}$ and $\mathrm{Na}_{2} \mathrm{SeSO}_{3}$ at alkaline $\mathrm{pH}, 10.4$, and $50 \pm 2{ }^{\circ} \mathrm{C}$ bath temperature at $2.30 \mathrm{~h}$ deposition time. Formation of thin films is well dependant on various preparative parameters such as, deposition time, bath temperature, $\mathrm{pH}$ and precursor concentration. These parameters were optimized during initial stage of thin film synthesis.

After desired deposition time deposited film was removed from bath and washed with double distilled water and dried at room temperature in air. Deposited film was yellowish red in colour and designated as $\mathrm{Cd}\left(\mathrm{S}_{0.8} \mathrm{Se}_{0.2}\right)$.

\section{Characterization of thin film}

Thickness of film was measured using surface profiler (AMBIOS XP-1). Optical absorption spectra were taken by using a UV-Vis-NIR spectrophotometer (Shimadzu, UV-1800). Structural properties and crystallite size were carried out using an X-ray diffractometer (Bruker AXS, D8) using Cu Ka (l=1.5418 Å). Surface morphology and the elemental composition of the as-deposited thin films were characterized using field-emission scanning electron microscopy (FESEM) equipped with an energy dispersive X-ray spectroscopy (EDS) analyzer (Hitachi, S-4700). PEC measurements were carried out using a semiconductor parameter analyzer (Keithley SCS-4200 Semiconductor) characterization unit using $500 \mathrm{~W}$ tungsten filament lamp (intensity $30 \mathrm{~mW} \mathrm{~cm}^{-2}$ ) with sulfide/polysulfide electrolyte.

\section{Results and Discussion}

\section{Formation Growth mechanism}

Main principle behind the film formation is slow ion-byion condensation of ions followed by multi nucleation process. Precipitation of metal chalcogenide thin films is occurred when ionic products $(\mathrm{Kp})$ of $\mathrm{Cd}^{2+}, \mathrm{S}^{2-}$ and $\mathrm{Se}^{2-}$ ions exceed solubility product (Ksp) of $\mathrm{Cd}(\mathrm{SSe}$ ) in films. Slow release of metal and chalcogen ions from respective complex results into highquality and well-adherent thin films formation [7-9].

\section{Optical absorption studies}

Figure 1 shows optical absorption spectrum of $\mathrm{Cd}\left(\mathrm{S}_{0.8} \mathrm{Se}_{0.2}\right)$ thin film recorded using UV-VisNIR spectrophotometer in 200$1100 \mathrm{~nm}$ wavelength range. Maximum light absorption edge observed at $650 \mathrm{~nm}$. Fundamental absorption corresponds to electron excitation from valance band to conduction band, used to determine value of optical band gap energy. Optical data were demonstrated using following eq. (1) as follows,

$$
\alpha=\frac{A(h \vartheta-E g)^{n}}{h \vartheta}
$$

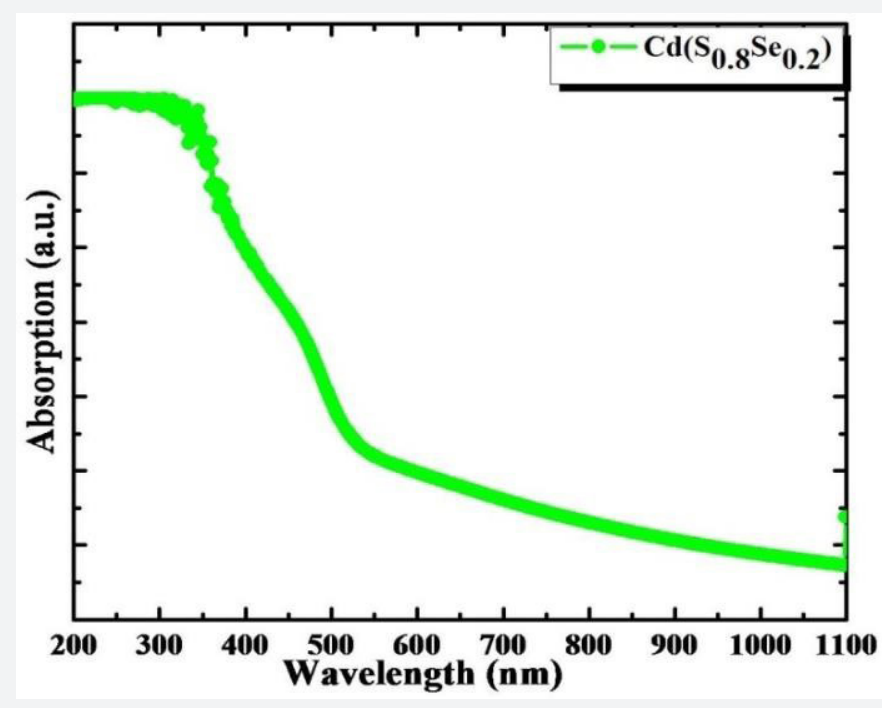

Figure 1: Optical absorption spectrum of $\mathrm{Cd}\left(\mathrm{S}_{0.8} \mathrm{Se}_{0.2}\right)$ thin film. 
where, $\mathrm{A}$ is a parameter that depends on the transition probability, h is Planck constant, $E g$ is optical band gap energy of material, and exponent depends on the type of transition. The values of $n$ for direct allowed, indirect allowed, direct forbidden and indirect forbidden transitions are 1/2, 2, 3/2 and 3 , respectively (Figure 1).

From optical absorption spectrum clearly demonstrated that linear nature of plot confirms direct allowed type transition mechanism.

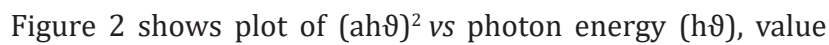
of optical band gap was calculated by extrapolating straight-line portion to X-axis. Obtained optical band gap energy is $2.13 \mathrm{eV}$, which is consistent with other reported ternary CdSSe thin films [7]. 3.3. X-ray diffraction study

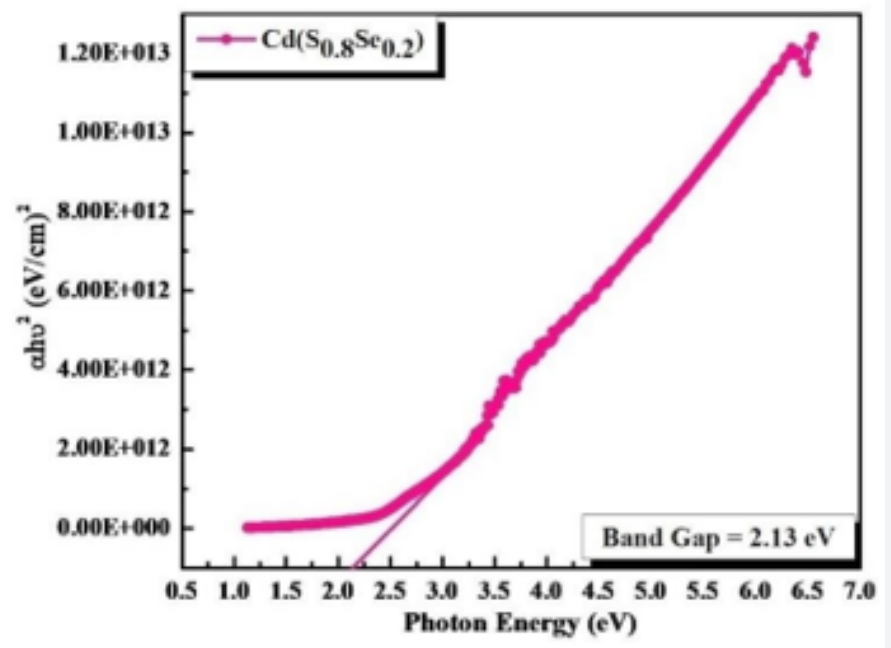

Figure 2: Plot of optical Band Gap energy.

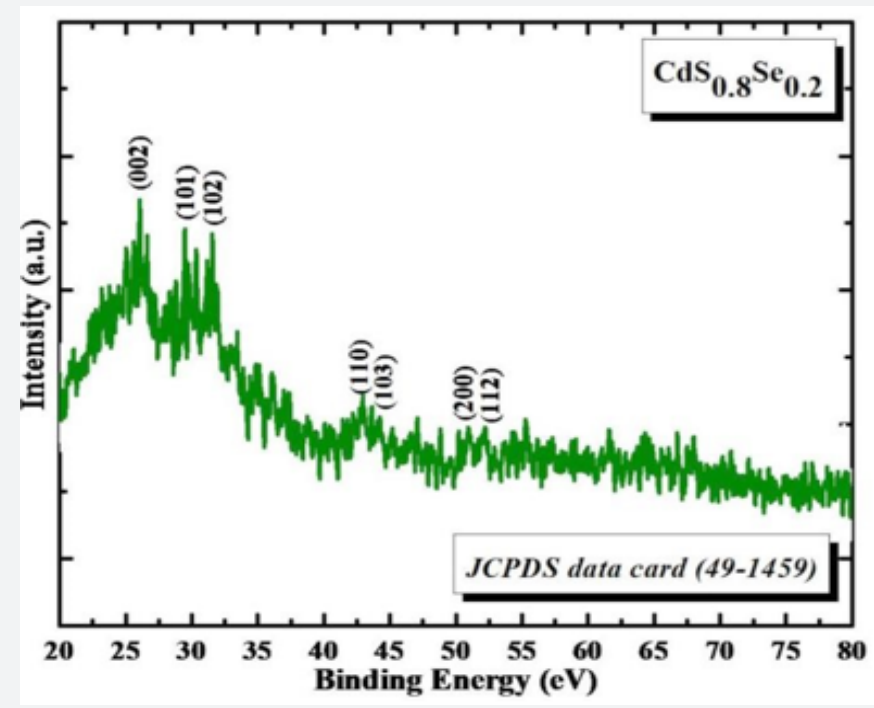

Figure 3: XRD pattern of deposited thin film.

Figure 3 indicates typical X-ray diffraction pattern of $\mathrm{Cd}\left(\mathrm{S}_{0.8} \mathrm{Se}_{0.2}\right)$ thin film deposited by using APT method. All diffraction peaks are corresponding to (002), (101), (102),

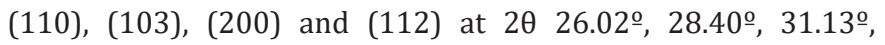
$42.80^{\circ}, 44.93^{\circ}, 50.89^{\circ}$ and $52.07^{\circ}$ of hexagonal crystal structure. Calculated d-values are in well-agreement with standard d-values (JCPDS card no. 49-1459) for an (hkl) plane, confirms formation of thin films with a pure phase material.

Crystallite size is calculated by using known Scherrer formula and calculated crystallite size is $55 \mathrm{~nm}$. Thickness of thin film is 728nm measured by using surface profiler analysis. Crystalline nature and phase pure formed thin films are highly favorable for enhanced light absorption in solar cell application [8].

\section{Field emission scanning electron microscopy}

Surface morphology of thin films carried out by using FESEM study. Figure 4 demonstrates FESEM micrographs at different resolution of $\mathrm{Cd}\left(\mathrm{S}_{0.8} \mathrm{Se}_{0.2}\right)$ thin film. Low resolution FESEM image of Figure 4 (a) point out void free and well adherent film formation occurs via APT method. It shows twisted nest-like surface morphology is observed overall substrate surface. 


\section{Academic Journal of Polymer science}

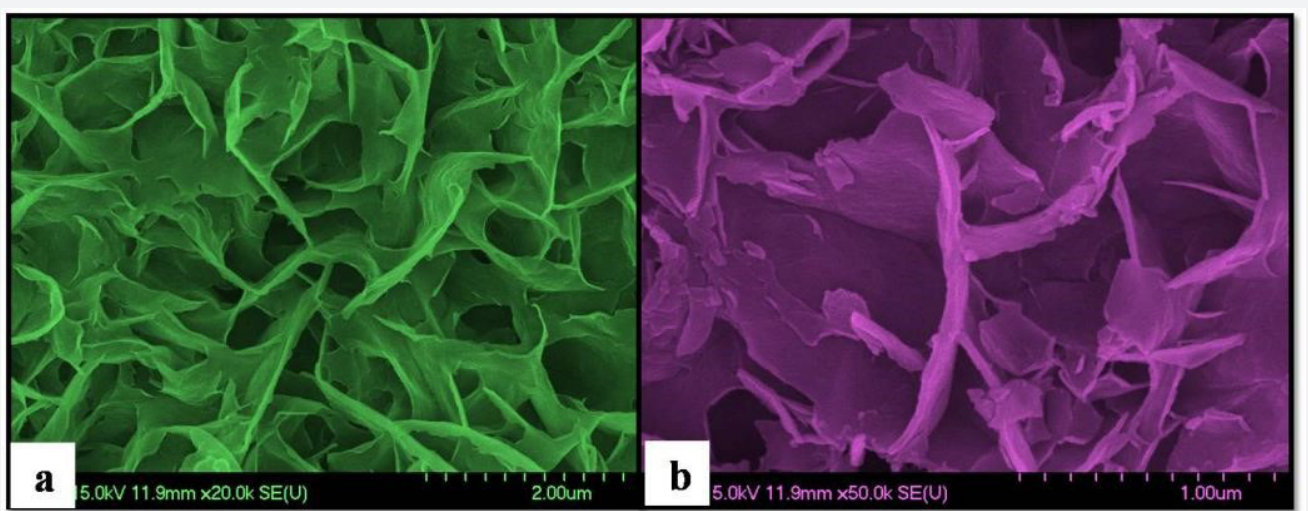

Figure 4: FESEM micrographs, (a) Low resolution FESEM image and (b) High resolution FESEM image.

High resolution FESEM images of Figure 4(b) clearly illustrate that twisting of nest-like morphology with irregularly grown sharp edged flakes. Such huge number of flakes winds together and formation of large network of nest-like morphology is observed from high resolution micrograph. This obtained surface morphology is beneficial for improve light absorption potential may due to crystalline nature and large surface area of nest-like morphology with twisted flakes [9].

\section{Energy dispersive spectroscopy}

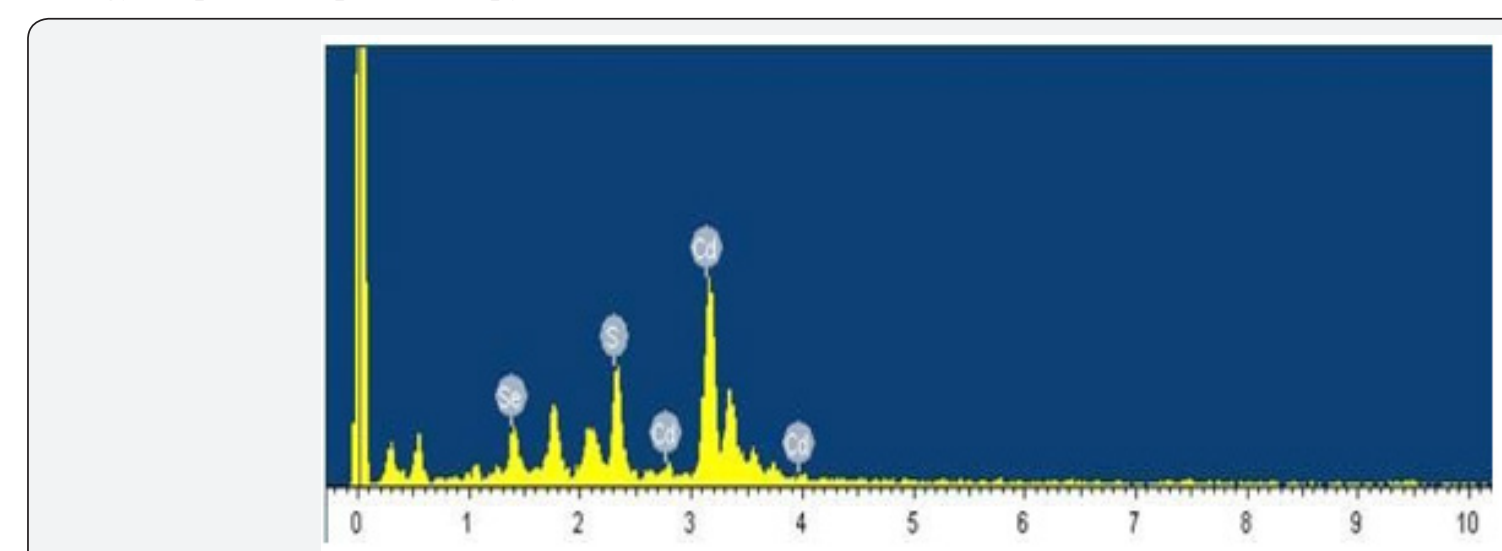

Figure 5: EDS spectrum of $\mathrm{Cd}\left(\mathrm{S}_{0.8} \mathrm{Se}_{0.2}\right)$ thin film.

Quantitative analysis of element is confirmed through EDS study. Figure 5 shows typical EDS spectrum of deposited thin film.
EDS spectrum shows peaks at 3.13, 2.50 and $1.38 \mathrm{keV}$ confirm the presence of Cd, S and Se elements respectively [7].

\section{Photoelectrochemical performance}

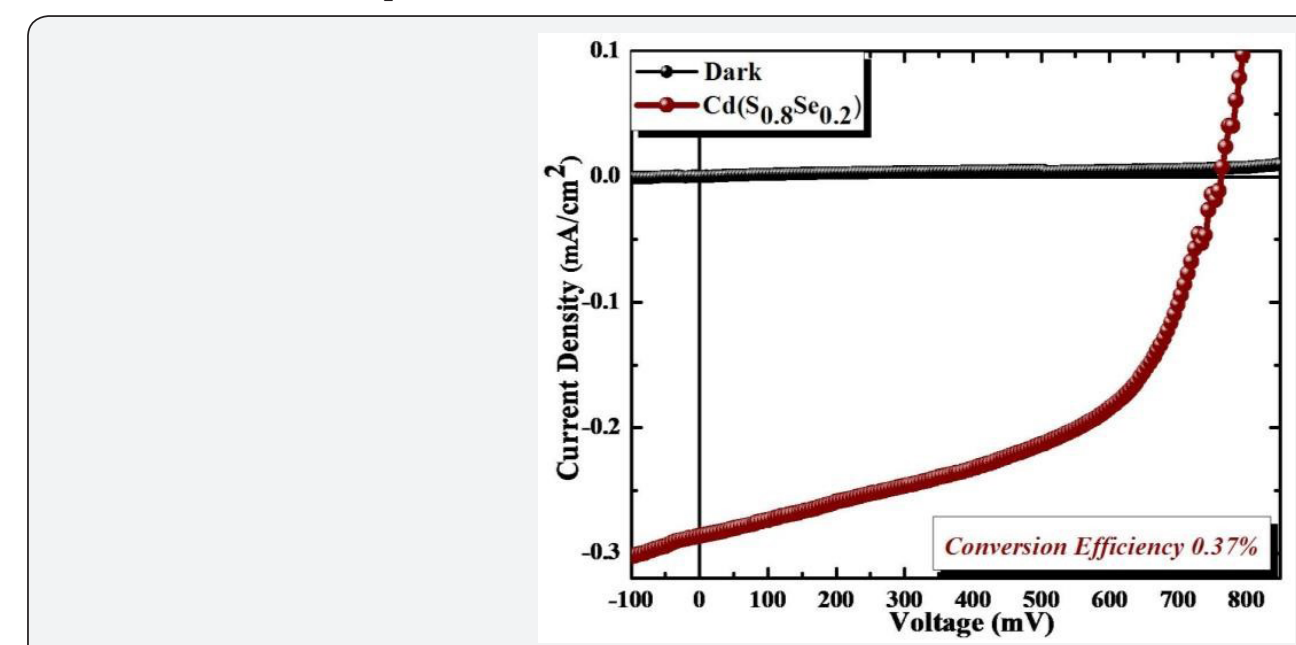

Figure 6: PEC performance of $\mathrm{Cd}\left(\mathrm{S}_{0.8} \mathrm{Se}_{0.2}\right)$ thin film. 
PEC performance of $\mathrm{Cd}\left(\mathrm{S}_{0.8} \mathrm{Se}_{0.2}\right)$ thin film was measured with standard two-electrode system. Figure 6 shows J-V curve of PEC cells. PEC performance was measured by forming $\mathrm{Cd}\left(\mathrm{S}_{0.8} \mathrm{Se}_{0.2}\right)$ thin film as working photoelectrode with active area $1 \mathrm{~cm}^{2}$ and graphite $\operatorname{rod}(G)$ as counter electrode in $0.5 \mathrm{M}$ sulfide/polysulfide redox electrolyte. J-V measurements were done under illumination of light using $500 \mathrm{~W}$ tungsten filament lamp (Intensity of $30 \mathrm{~mW} /$ $\mathrm{cm}^{2}$ ). In dark, $J$ - $V$ curve shows diode-like rectifying characteristics. Upon illumination, curve is obtained at fourth quadrant, indicating

Table 1: PEC parameter of $\mathrm{Cd}\left(\mathrm{S}_{0.8} \mathrm{Se}_{0.2}\right)$ thin film.

generation of electricity and n-type conductivity nature [6-7].

Fill factor (FF) and power conversion efficiency $(\eta \%)$ of thin film were calculated by using equations (2) and (3) as follows,

$$
\begin{aligned}
& F F=\left(\frac{J_{\max } \times V_{\max }}{J_{s c} \times V_{o c}}\right) \\
& \eta(\%)=\left(\frac{J_{s c} \times V_{o c}}{P_{i n}} \times F F \times 100\right)
\end{aligned}
$$

\begin{tabular}{|c|c|c|c|c|c|c|c|}
\hline Sample Code & $\mathbf{E g}(\mathbf{e V})$ & Jsc $\left(\mathbf{m A ~ \mathbf { ~ m } ^ { - 2 } )}\right.$ & Voc (mV) & Jmax $\left(\mathbf{m A ~ c m}^{-2}\right)$ & Vmax (mV) & $\mathbf{F F}$ & $\eta(\mathbf{m})$ \\
\hline $\mathrm{CdS}_{0.8} \mathrm{Se}_{0.2}$ & 2.13 & 0.288 & 765 & 0.184 & 603 & 0.5 & 0.37 \\
\hline
\end{tabular}

where, $J_{\max }$ and $V_{\max }$ are maximum short-circuit current density and maximum open circuit voltage, $\mathrm{P}_{\text {in }}$ is input light intensity $\left(30 \mathrm{~mW} / \mathrm{cm}^{2}\right) . J s c$ is short-circuit current density and $V_{o c}$ is open circuit voltage. From $J-V$ measurement, short circuit current density $\left(U_{s c}\right)$ is $0.288 \mathrm{~mA} \mathrm{~cm}^{-2}$ and that of open circuit voltage $\left(V_{o c}\right) 765 \mathrm{mV}$. Calculated power conversion efficiency is $0.37 \%$ for $\mathrm{Cd}\left(\mathrm{S}_{0.8} \mathrm{Se}_{0.2}\right)$ thin film. Overall obtained conversion efficiency might be due to good crystallinity and developed surface morphology with large surface area [9]. Table 1 shows calculated PEC parameter.

\section{Conclusion}

Developed facile, cost-effective APT method shows potential for synthesis of thin films for solar cell. Synthesized thin film show promising properties favorable for photoelectrochemical performance is investigated. Optical study showed light absorption in visible region of solar spectrum and direct allowed transition mechanism. From XRD pattern it confirmed that formation of pure phase hexagonal crystal structure with nanocrystalline nature. FESEM analysis demonstrated synthesized surface morphology is void free and having large surface area for efficient light absorption. EDS pattern confirmed presence of $\mathrm{Cd}^{2+}, \mathrm{S}^{2-}$ and $\mathrm{Se}^{2-}$ elements in synthesized thin film. PEC performance indicated conversion efficiency of $0.37 \%$.

\section{References}

1. Wang M, Shang X, Yu X, Liu R, Xie Y, et al. (2014) Graphene-CdS quantum dots-polyoxometalate composite films for efficient photoelectrochemical water splitting and pollutant degradation. Phys Chem Chem Phys 47: 26016-26023.

2. Lu C, Zhang L, Zhang Y, Liu S, Liu G (2014) Fabrication of CdS/CdSe bilayer thin films by chemical bath deposition and electrodeposition, and their photoelectrochemical properties. Appl Surf Sci 319: 278-284.

3. Bhuvana KP, Elanchezhiyan J, Gopalakrishnan N, Balasubramanian T (2009) Optimization of Zn1-xAlxO film for antireflection coating by RF sputtering. J Alloys Compd 473(1-2): 534-537.

4. Chavhan SD, Mane RS, Ganesh T, Wonjoo L, Han SH, et al. (2009) J Alloys Compd 210: 474.

5. Liu Y, Xu Y, Li JP, Zhang B, Wu D et al. (2006) Mater Res Bull 99: 41.

6. Khot KV, Mali SS, Kharade RR, Mane RM, Patil PS, et al. (2014) Novelapproach for fabrication of CdS thin films for photoelectrochemical solar cell application. J Mater Sci: Mater Electron. 25(12): 5606-5617.

7. Khot KV, Mali SS, Pawar NB, Kharade RR, Mane RM, et al. (2014) Development of nanocoral-like Cd(SSe) thin films using an arrested precipitation technique and their application. New J Chem 38: 59645974 .

8. Khot KV, Dongale TD, Mali SS, Hong CK, Kamat RK, et al. (2017) Deposition, characterizations and photoelectrochemical performance of nanocrystalline $\mathrm{Cu}-\mathrm{In}-\mathrm{Cd}-\mathrm{S}-\mathrm{Se}$ thin films by hybrid chemical process. Journal of Materials Science 52(16): 9709-9727.

9. Khot KV, Mali SS, Pawar NB, Mane RM, Kondalkar VV, et al. (2014) Novel synthesis of interconnected nanocubic $\mathrm{PbS}$ thin films by facile aqueous chemical route. J Mater Sci: Mater Electron 25(9): 3762-3770.

\section{Your next submission with Juniper Publishers will reach you the below assets}

- Quality Editorial service

- Swift Peer Review

- Reprints availability

- E-prints Service

- Manuscript Podcast for convenient understanding

- Global attainment for your research

- Manuscript accessibility in different formats

( Pdf, E-pub, Full Text, Audio)

- Unceasing customer service

Track the below URL for one-step submission

https://juniperpublishers.com/online-submission.php 